\title{
PENGEMBANGAN KONSTRUK SISTEM PEMBELAJARAN PADA PENDIDIKAN TINGGI VOKASI
}

\author{
I Made Suarta \\ Politeknik Negeri Bali \\ Email: i_md_suarta@yahoo.co.id
}

\begin{abstract}
Abstrak: Pengembangan Konstruk Sistem Pembelajaran pada Pendidikan Tinggi Vokasi. Sistem pembelajaran di politeknik perlu menyesuaikan dengan kebutuhan-kebutuhan terkini dalam menyiapkan lulusan untuk memiliki pekerjaan dengan keahlian terapan tertentu. Penelitian ini bertujuan: (1) Mendeskripsikan persepsi mahasiswa tentang sistem pembelajaran yang diterapkan oleh dosen/instruktur di politeknik; dan (2) Memperoleh model pengukuran konstruk sistem pembelajaran pendidikan tinggi vokasi. Penelitian dilaksanakan dengan pendekatan kuantitatif non-eksperimen, menggunakan kuesioner sebagai alat penumpul data. Sampel penelitian adalah mahasiswa tingkat akhir Politeknik Negeri Bali tahun akademik 2009/2010. Ukuran sampel penelitian sebanyak 244. Teknik sampling yang digunakan adalah proportional random sampling. Data dianalisis secara deskriptif kuantitatif dan analisis faktor konfirmatori. Hasil penelitian menunjukkan: (1) Menurut persepsi mahasiswa, kemampuan dosen dan instruktur dalam mengelola program pembelajaran di politeknik secara umum termasuk dalam kategori baik; (2) Model pengukuran konstruk sistem pembelajaran pendidikan tinggi vokasi terdiri atas indikator-indikator: pembelajaran yang berpusat pada peserta didik, pembelajaran yang berpusat pada kerja, serta pembelajaran yang berfokus pada pengembangan atribut-atribut keterampilan peserta didik. Indikator-indikator ini dinyatakan valid dan reliabel dengan nilai koefisien struktural $(\lambda)$ bervariasi antara 0,78 hingga 0,81, serta nilai reliabilitas konstruk sebesar 0,85.
\end{abstract}

Kata-kata kunci: pendidikan tinggi vokasi, sistem pembelajaran, keterampilan employability.

\section{THE CONSTRUCT DEVELOPMENT OF LEARNING SYSTEM IN HIGHER VOCATIONAL EDUCATION}

\begin{abstract}
The Construct Development of Learning System in Higher Vocational Education. Learning system in polytechnic necessary to adapt the current needs in preparing graduates to have jobs with specific applied skills. The research purposes are: (1) describe students' perceptions about the learning system adopted by the lecturer/instructor at the polytechnic, and (2) Obtain a measurement model of learning system in the higher vocational education. The experiment was conducted by non-experimental quantitative approach, using questionnaires. The sample of study was last year students of Bali State Polytechnic in academic year 2009/2010. The sample size was 244, selected using proportional random sampling. Data were analyzed descriptively quantitative and confirmatory factor analysis. The research results showed: (1) According to the perceptions of students, the ability of lecturers and instructors to manage learning system in the polytechnics are generally good categorized, (2) the measurement model of learning system in the higher vocational education consists of: learning that learner-centered, learning work-centered, and learning that focuses on developing the attributes of skill. These indicators are valid and reliable with the structural coefficient $(\lambda)$ varies between 0.78 to 0.81 , and construct reliability of 0.85 .
\end{abstract}

Keywords: higher vocational education, learning system, employability skills.

\section{PENDAHULUAN}

Paradigma ekonomi global saat ini ditandai oleh berkembangnya ekonomi berbasis pengetahuan. Daya saing di era ekonomi berbasis pengetahuan berpijak pada keunggulan kompetitif, terbentuk dari tiga unsur yang terkait satu sama lain: (1) modal manusia, kemampuan organisasi, dan (3) penguasaan 
kompetensi. Ketiganya harus berjalan serempak, di mana kemampuan organisasi dan penguasaan kompetensi itu sendiri pada dasarnya juga tergantung pada keunggulan modal manusia yang menanganinya (Zuhal, 2008:16). Industri di era ekonomi berbasis pengetahuan membutuhkan pekerja-pekerja yang diistilahkan dengan knowledge workers (Hager \& Holland, 2006:4).

Sistem ekonomi baru ini memerlukan para pekerja dengan sejumlah kemampuankemampuan yang bersifat luas termasuk keterampilan-keterampilan personal dan interpersonal (Rojewski, 2002). Selain memiliki keterampilan teknis dalam bidangnya, industri saat ini sangat membutuhkan pekerja-pekerja yang memiliki keterampilan bersifat generik (employability skills). Keterampilan berpikir tingkat tinggi seperti pengambilan keputusan dan pemecahan masalah, fleksibilitas, berpikir kreatif, kemampuan mengelola konflik, mengelola informasi dan sumberdaya, serta kapasitas untuk melakukan refleksi juga diharapkan dari para pekerja masa depan (Cairney, 2000).

Fenomena ini telah menjadi trend di kalangan industri ketika rekruitmen karyawan baru. Industri tidak saja mensyaratkan para pencari kerja memiliki keterampilan teknis (technical skills) sesuai bidangnya, tetapi juga mensyaratkan para pencari kerja memiliki keterampilan-keterampilan yang sifatnya nonteknis (non-technical skills) seperti personal skills, interpersonal skills, teamworking, dan sebagainya.

Perubahan karakteristik dunia kerja ini memberikan tantangan secara terus-menerus pada dunia pendidikan. Treleaven \& Voola
(2008:160) menyatakan, "Graduate employability is a central concern of contemporary higher education." Politeknik sebagai penyelenggara pendidikan tinggi vokasi diharapkan dapat membekali lulusannya dengan berbagai keterampilan yang sesuai kebutuhan pasar kerja, sehingga setelah lulus mereka dapat segera terserap ke dunia kerja. Selain itu, juga perlu membekali lulusannya dengan employability skills untuk pengembangan karir profesional di masa mendatang.

Salah satu aspek penting dalam pendidikan di politeknik adalah proses pembelajaran. Hal ini menjadi penting bagi politeknik sebagai penyelenggaran pendidikan tinggi vokasi karena sifat pendidikan di politeknik dirancang untuk membekali lulusannya dengan keahlian terapan tertentu. Terdapat beberapa faktor yang saling berinteraksi dalam proses pembelejaran, salah satunya adalah sistem pembelajaran yang dikembangkan oleh dosen/instruktur (ShyiHuey, 2005:2). Pendekatan sistem pembelajaran di politeknik perlu menyesuaikan dengan kebutuhan-kebutuhan terkini dalam menyiapkan lulusan untuk memiliki pekerjaan dengan keahlian terapan tertentu.

Sistem pembelajaran merupakan gambaran tentang pendekatan yang digunakan oleh dosen dan instruktur dalam pelaksanaan kegiatan pembelajaran (Chappell, 2003:3). Sistem pembelajaran di politeknik perlu dikembangkan dalam tiga aspek yaitu: agar mahasiswa memahami dan menguasai bidang keahliannya (know-what), agar mahasiswa memahami bagaimana suatu pekerjaan dilakukan (knowhow), agar mahasiswa memiliki pemahaman tentang mengapa suatu pekerjaan dilakukan (know-why). 
Saat ini pendekatan pembelajaran pada pendidikan vokasi mengarah kepada: (1) pembelajaran yang berpusat pada peserta didik (learner-centered), (2) pembelajaran yang berpusat pada pekerjaan (work-centered), dan (3) pembelajaran yang berfokus pada pengembangan atribut-atribut keterampilan (attribute-focused) (Chappell, 2003:3). Pembelajaran aktif atau konsep-konsep yang berhubungan dengan student-centered learning dapat diimplementasi-kan melalui beberapa metode pembelajaran (Tempelaar \& Nijhuis, 2007:228), dan memerlukan peran serta aktif mahasiswa selama proses pembelajaran. Pendekatan learner-centered mengasumsikan bahwa mahasiswa berperan secara aktif dan mempunyai potensi yang tidak terbatas untuk dikembangkan, konstruksi pengetahuan dilakukan bersama, dan belajar dicapai melalui keterlibatan dalam berbagai aktivitas. Kilic (2010:80) mengungkapkan melalui pendekatan belajar learner-centered pembentukan berpikir kreatif, reflektif, dan keterampilan berpikir kritis dapat lebih mudah dilakukan.

Berdasarkan latar belakang tersebut, maka dipandang perlu untuk mengembangkan suatu model yang dapat mengukur konstruk sistem pembelajaran di politeknik. Penelitian ini bertujuan: (1) Mendeskripsikan persepsi mahasiswa tentang sistem pembelajaran yang diterapkan oleh dosen/instruktur di politeknik; dan (2) Memperoleh model pengukuran konstruk sistem pembelajaran pendidikan tinggi vokasi.

\section{METODE PENELITIAN}

Penelitian ini menggunakan pendekatan kuantitatif non-eksperimen dan bersifat ex-post facto (Bordens \& Abbott, 2008:216). Penelitian dilaksanakan dengan metode survei menggunakan kuesioner sebagai alat pengumpul data. Metode survei merupakan salah satu bentuk penelitian kuantitatif non-eksperimen (Mitchell \& Jolley, 2007:208) yang bertujuan untuk mengumpulkan data dari suatu sampel yang terpilih mewakili populasi untuk kemudian dilakukan generalisasi guna mengetahui gambaran umum karakteristik populasi (Gall et.al, 2003:223).

Target responden penelitian ini adalah mahasiswa tingkat akhir tahun akademik 2009/2010. Ukuran sampel penelitian sebanyak 244. Teknik sampling yang digunakan adalah proportional random sampling (Lohr, 2008:107) di mana sampel penelitian dialokasikan secara proporsional berdasarkan program studi.

Pengumpulan data lapangan dilaksanakan pada bulan Februari 2010 hingga bulan Juni 2010. Data dikumpulkan dengan cara selfadministered questionnaires, di mana responden menjawab pertanyaan-pertanyaan yang terdapat dalam kuesioner tanpa adanya bantuan dari petugas pengumpul data (De Leeuw, 2008:113).

Data tentang sistem pembelajaran diungkap dengan Kuesioner Sistem Pembelajaran, dikembangkan dan diadaptasi dari "Changing Pedagogy: Contemporary Vocational Learning" oleh Chappell (2003) serta beberapa hasil kajian literatur yang relevan (Smith \& Comyn, 2003; Shyi-Huey, 2005; dan Cleary, et al., 2007). Cappell mengidentifikasi sistem pembelajaran dalam tiga indikator, meliputi: (1) pendekatan pembelajaran yang berpusat pada peserta didik, (2) pendekatan pembelajaran yang berpusat pada pekerjaan, dan (3) pendekatan pembelajaran yang berfokus pada pengembangan atribut- 
atribut keterampilan. Hanya saja butir-butir dari masing-masing indikator ini tidak teridentifikasi secara jelas. Penjabaran masing-masing indikator ke dalam komponen-komponen lebih kecil dilakukan melalui kajian terhadap beberapa literatur yang relevan. Komponen-komponen inilah menjadi butir-butir pertanyaan dalam Kuesioner Sistem Pembelajaran (KSP).

Instrumen KSP dikembangkan guna melihat indikator-indikator sistem pembelajaran pada pendidikan vokasi dan sejauhmana hal itu sudah diterapkan dalam proses pembelajaran. Secara keseluruhan instrumen KSP memuat 30 butir pertanyaan. Instrumen KSP menggunakan skala Likert dengan lima alternatif jawaban yaitu $5=$ sangat yakin, $4=$ yakin, $3=$ ragu-ragu, $2=$ tidak yakin, dan 1 = sangat tidak yakin

Jumlah kuesioner yang diedarkan dalam penelitian ini sebanyak 250. Terdapat 216 kuesioner yang diisi secara benar dan lengkap serta layak untuk dianalisis lebih lanjut. Dengan demikian tingkat partisipasi responden (respons rate) dalam penelitian ini mencapai $86,4 \%$. Hasil uji validitas instrumen penelitian dengan menggunakan koefisien korelasi pearson product moment terdapat dua butir pertanyaan yang tidak memenuhi kriteria valid (signifikan pada taraf $\alpha=5 \%$ ). Dengan demikian terdapat 28 butir pertanyaan yang memenuhi kriteria valid dan reliabel dengan nilai koefisien korelasi pearson product moment antara 0,379 (terendah) sampai 0,792 (tertinggi), serta nilai reliabilitas (Cronbach's Alpha) 0,917.

Data hasil penelitian dianalisis secara deskriptif kuantitatif dan analisis faktor konfirmatori. Analisis deskriptif kuantitatif dimaksudkan untuk mengetahui persepsi mahasiswa tentang sistem pembelajaran yang sudah diterapkan oleh dosen/instruktur di politeknik.

Analisis faktor konfirmatori dimaksudkan untuk mengkonfirmasi apakah pendekatan pembelajaran yang berpusat pada peserta didik, pendekatan pembelajaran yang berpusat pada pekerjaan, dan pendekatan pembelajaran yang berfokus pada pengembangan atribut-atribut keterampilan dapat menjelaskan konstruk sistem pembelajaran pada pendidikan vokasi secara valid dan reliabel. Analisis faktor konfirmatori dilakukan dengan bantuan program LISREL 8,51 for Windows. Kriteria penerimaan yang digunakan dalam penelitian ini adalah standardized loading factor dari masing-masing indikator $(\lambda) \geq 0,40$, t-value standardized solution $\geq 1.96$, dan Construct Reliability $(\mathrm{CR}) \geq$ 0.70 (Hair et al., 2006).

\section{HASIL PENELITIAN DAN PEMBAHASAN}

Data hasil penelitian menunjukkan jumlah skor minimal konstruk sistem pembelajaran adalah 84, jumlah skor maksimal 139, rerata sebesar 109,78, nilai tengah 110 , modus sebesar 112, dan simpangan baku 10,92. Rerata skor hasil penelitian $(M=109,78)$ termasuk kategori tinggi. Terdapat $8,8 \%$ responden mempersepsikan sistem pembelajaran dalam kategori sedang, dan sebanyak 91,2\% termasuk dalam kategori tinggi dan tinggi sekali. Secara rinci deskripsi data untuk masing-masing indikator sistem pembelajaran disajikan pada Tabel 1. 
Tabel 1. Deskripsi Data Indikator-Indikator Sistem Pembelajaran

\begin{tabular}{|l|r|r|r|}
\hline Deskripsi Data & \multicolumn{1}{|c|}{ SP1 } & \multicolumn{1}{|c|}{ SP2 } & \multicolumn{1}{|c|}{ SP3 } \\
\hline \hline Mean & 43.21 & 31.80 & 34.76 \\
\hline Median & 44 & 32 & 35 \\
\hline Modus & 44 & 32 & 36 \\
\hline Std. Deviasi & 4.72 & 3.36 & 4.37 \\
\hline Skor Minimum & 31 & 22 & 24 \\
\hline Skor Maximum & 55 & 40 & 45 \\
\hline Jumlah Skor & 9334 & 6869 & 7509 \\
\hline Skor Kriteria & 11880 & 8640 & 9720 \\
\hline Pencapaian Skor & $78.6 \%$ & $79.5 \%$ & $77.3 \%$ \\
\hline
\end{tabular}

Hasil analisis faktor konfirmatori konstruk sistem pembelajaran dalam bentuk standardized solution seperti pada Gambar 1.

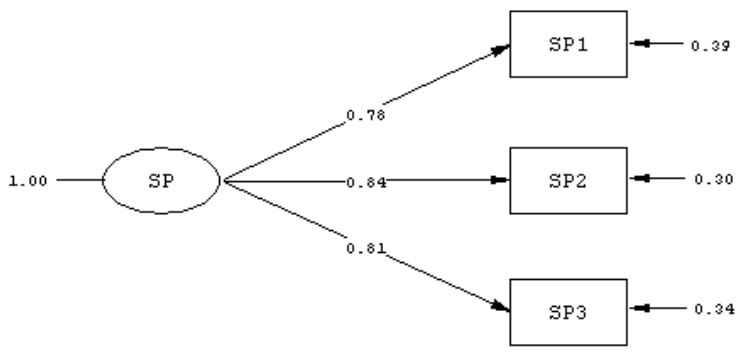

Keterangan:

$\mathrm{SP}=$ Sistem Pembelajaran

SP1 = Pembelajaran berpusat pada peserta didik

SP2 $=$ Pembelajaran berpusat pada pekerjaan

SP3 = Pembelajaran berfokus pengembangan atribut

Gambar 1. Hasil Analisis Konfirmatori Variabel Sistem Pembelajaran

Hasil analisis faktor konfirmatori menunjukkan nilai muatan faktor $(\lambda)$ dari masing-masing indikator bervariasi antara 0,78 hingga 0,81 , serta $t$-value lebih besar dari 1,96. Nilai muatan faktor ini lebih besar dari kriteria penerimaan yakni 0,40. Berdasarkan hasil ini dapat disimpulkan bahwa, pendekatan pembelajaran yang berpusat pada peserta didik (SP1), pendekatan pembelajaran yang berpusat pada pekerjaan (SP2), dan pendekatan pembelajaran yang berfokus pada pengembangan atribut-atribut keterampilan (SP3) merupakan variabel-variabel yang valid dalam menjelaskan konstruk sistem pembelajaran pada pendidikan vokasi.

Sementara itu, hasil perhitungan reliabilitas menunjukkan reliabilitas konstruk $=0,85$. Nilai ini lebih besar dari kriteria penerimaan 0,70 . Hal ini berarti bahwa reliabilitas model pengukuran dari variabel laten sistem pembelajaran adalah baik.

Berdasarkan hasil analisis data menunjukkan bahwa sistem pembelajaran di politeknik menurut persepsi mahasiswa termasuk kategori tinggi dengan prosentase pencapaian jumlah skor $78,4 \%$. Selaras dengan definisi sistem pembelajaran pendidikan vokasi maka hasil penelitian ini dapat dimaknai bahwa kemampuan dosen dan instruktur dalam mengelola program pembelajaran di politeknik dengan menggunakan pendekatan pembelajaran yang berpusat pada peserta didik, pembelajaran yang berpusat pada kerja, serta pembelajaran yang berfokus pada pengembangan atribut-atribut keterampilan peserta didik (Chappell, 2003:3) secara umum berada dalam kategori tinggi. Namun demikian, rerata jumlah skor sistem pembelajaran $(\bar{X}=109,78)$ berada pada kisaran nilai tengah kategori tinggi dan prosentase pencapaian jumlah skor $(78,4 \%)$ masih cukup jauh dari skor maksimal (100\%). Hasil ini sesuai dengan kecenderungan di mana sekitar 8,8\% responden berpendapat sistem pembelajaran di politeknik termasuk kategori sedang.

Apabila persepsi mahasiswa tentang sistem pembelajaran ini dimaknai sebagai kemampuan dosen dan instruktur dalam mengelola pembelajaran, maka dosen dan instruktur telah menerapkan pendekatan pembelajaran pendidikan vokasi pada jalur yang benar. Hanya saja karena masih terdapat sekitar $8,8 \%$ 
responden berpendapat sistem pembelajaran di politeknik termasuk kategori sedang, maka diperlukan upaya-upaya perbaikan dalam meningkatkan efektifitas pembelajaran di politeknik. Sangat beralasan perlunya berbagai upaya agar dosen maupun instruktur di politeknik ditingkatkan kapasitas dan kemampuannya dalam mengelola program pembelajaran dengan menggunakan pendekatan pembelajaran yang berpusat pada peserta didik, pembelajaran yang berpusat pada kerja, serta pembelajaran yang berfokus pada pengembangan atribut-atribut keterampilan peserta didik. Upaya-upaya perbaikan dilakukan dengan tetap mengedapankan peran dosen sebagai mitra pembelajaran maupun fasilitator. Sejalan dengan karakteristik pendidikan vokasi yang lebih menekankan pada kemampuan unjuk kerja, penyiapan untuk mendapatkan pekerjaan, dan menekankan pada pengembangan keterampilan (Finch \& Crunkilton, 1999:14) maka sudah sepatutnya pendekatan pembelajaran yang berpusat pada peserta didik, pembelajaran yang berpusat pada kerja, serta pembelajaran yang berfokus pada pengembangan atribut-atribut keterampilan peserta didik diterapkan di politeknik.

Keterlibatan mahasiswa secara aktif dalam proses pembelajaran merupakan bentuk dari pendekatan pembelajaran yang berpusat pada peserta didik, berorientasi pada pekerjaan, serta berfokus pada pengembangan atribut-atribut keterampilan. Keterlibatan mahasiswa secara aktif dalam proses pembelajaran mampu memberikan dampak secara positif terhadap hasil-hasil belajar seperti berkembangnya keterampilan mahasiswa serta dapat mengembangkan keterampilan berpikir tingkat tinggi (Smart \& Csapo, 2007:451). Pembelajaran yang berpusat pada peserta didik juga memberikan manfaat seperti: memotivasi dan mendorong keterlibatan mahasiswa untuk aktif dalam belajar, mendorong mahasiswa menjadi lebih otonomi dalam belajar, serta dapat mengembangkan transferable personal skills (Berdrow \& Evers, 2010:3).

Pembelajaran yang berpusat pada peserta didik juga bermanfaat bagi lingkungan belajar di kelas serta institusi (Weimer, 2002:30). Dalam hal ini, jika mahasiswa terlibat secara aktif dalam pembelajaran, mereka akan termotivasi untuk bekerja secara keras, dapat menghayati karakteristik life-long learning, menguasai hard skills, soft skills, dan life-skills yang saling mendukung (Harsono, 2004:3).

Hasil analisis faktor konfirmatori menunjukkan indikator-indikator pembelajaran yang berpusat pada peserta didik, pembelajaran yang berpusat pada kerja, serta pembelajaran yang berfokus pada pengembangan atributatribut keterampilan peserta didik merupakan indikator-indikator yang valid dan reliabel dalam menjelaskan konstruk sistem pembelajaran di politeknik dengan reliabilitas konstruk sebesar 0,85 . Indikator pendekatan pembelajaran yang berpusat pada peserta didik mempunyai koefisien struktural 0,78. Indikator pendekatan pembelajaran yang berpusat pada pekerjaan mempunyai koefisien struktural 0,84 . Indikator pendekatan pembelajaran yang berfokus pada pengembangan atribut-atribut keterampilan mempunyai koefisien struktural 0,81 .

Apabila dicermati lebih lanjut koefisien struktural masing-masing indikator, dapat diketahui bahwa koefisien struktural indikator pendekatan pembelajaran yang berpusat pada 
peserta didik mempunyai nilai yang terendah dibandingkan dengan indikator lainnya. Hasil ini dapat ditafsirkan sebagai indikasi bahwa kemampuan indikator ini dalam menjelaskan konsep atau konstruk sistem pembelajaran masih lebih rendah dibandingkan dengan indikator yang lainnya. Sementara itu, indikator pendekatan pembelajaran yang berpusat pada pekerjaan mempunyai koefisien struktural yang tertinggi. Hal ini mengandung makna bahwa pendekatan pembelajaran yang berpusat pada pekerjaan memberikan kontribusi tertinggi dalam menjelaskan konstruk sistem pembelajaran pendidikan vokasi. Persepsi mahasiswa seperti ini menunjukkan bahwa mereka belajar di politeknik adalah berkenaan dengan pekerjaan. Hasil penelitian ini sejalan dengan pendapat Clarke \& Winch (2007:9) yang menyatakan pendidikan vokasi merupakan pendidikan yang mempersiapkan orang memiliki pekerjaan untuk kehidupan masa depannya.

Indikator pendekatan pembelajaran yang berpusat pada pekerjaan mempunyai rerata skor tertinggi yakni 3,975, kemudian diikuti oleh pendekatan pembelajaran yang berpusat pada peserta didik dengan rerata skor 3,928, sementara itu pendekatan pembelajaran yang berfokus pada pengembangan atribut-atribut keterampilan mempunyai rerata skor terendah yaitu 3,863. Hasil ini dapat dimaknai bahwa sistem pembelajaran di politeknik sudah mengarah pada pembelajaran yang mempersiapkan peserta didik untuk bekerja, namun masih kurang dalam hal pengembangan atibut-atribut keterampilan.

Gambaran tentang sejauh mana dosen dan instruktur di politeknik telah menerapkan sistem pembelajaran pendidikan vokasi menurut persepsi mahasiswa dapat dicermati dari tiga indikator penyusun konstruk sistem pembelajaran yang telah dinyatakan valid dan reliabel. Indikator pendekatan pembelajaran yang berpusat pada pekerjaan mempunyai rerata skor tertinggi yakni sebesar 3,975 dari skor maksimal 5. Indikator ini berkaitan dengan penerapan strategi pembelajaran yang memungkinkan mahasiswa belajar dalam suasana bekerja (Chappell, 2003:10) sehingga memiliki sejumlah keterampilan untuk memasuki dunia kerja. Mahasiswa mempersepsikan yakin dosen dan instruktur telah menerapkan pendekatan pembelajaran yang berorientasi pada pekerjaan selama proses pembelajaran. Apabila dicermati dari butir-butir yang menyusunnya, tampak bahwa semua butir memiliki rerata dalam kategori tinggi dan tinggi sekali, dengan rerata skor bervariasi dari 3,72 hingga 4,45 dalam skala skor maksimal 5. Skor tertinggi didapat oleh butir "kegiatan praktik kerja lapangan dapat meningkatkan pengetahuan dan keterampilan mahasiswa". Sedangkan skor terendah didapat oleh butir "kegiatan belajar senantiasa berorientasi pada realitas dan masalah dalam pekerjaan”. Hal ini mengindikasikan bahwa dosen dan instruktur telah mendorong kegiatan belajar dalam bentuk praktik kerja lapangan sehingga dapat meningkatkan pengetahuan dan keterampilan mahasiswa, hanya saja menurut persepsi mahasiswa kegiatan belajar masih perlu ditingkatkan dalam hal orientasi pada realitas dan masalah-masalah nyata dalam pekerjaan.

Indikator pendekatan pembelajaran yang berpusat pada peserta didik mempunyai rerata skor tertinggi kedua dengan rerata skor 3,928 dari skor maksimal 5. Indikator ini berkaitan 
dengan penerapan strategi pembelajaran yang memungkinkan mahasiswa belajar secara aktif (Chappell, 2003:10). Dalam pendekatan ini mahasiswa menjadi partisipan, kontributor dan elaborator dari pengetahuan dan keterampilan, sementara dosen atau instruktur berperan sebagai fasilitator, sebagai pemandu kegiatan belajar, serta pengelola sumber daya pelajaran. Mahasiswa mempersepsikan yakin dosen dan instruktur telah menerapkan pendekatan pembelajaran yang berpusat pada peserta didik sehingga mereka berpartisipasi aktif selama proses pembelajaran. Apabila dicermati dari butir-butir yang menyusunnya, tampak bahwa semua butir memiliki rerata dalam kategori tinggi dan tinggi sekali, dengan rerata skor bervariasi dari 3,44 hingga 4,40 dalam skala skor maksimal 5. Skor tertinggi didapat oleh butir "kegiatan belajar praktik dapat mendorong mahasiswa memahami materi pelajaran". Sedangkan skor terendah didapat oleh butir "dosen menyediakan waktu untuk membantu mahasiswa yang ketinggalan dalam belajar". Hal ini dapat dimaknai bahwa dosen dan instruktur telah mendorong mahasiswa aktif dalam kegiatan belajar praktik baik di lab, bengkel, studio, maupun workshop sehingga mahasiswa dapat memahami materi pelajaran dengan lebih, namun disisi lain dosen atau instruktur masih perlu meluangkan waktu untuk membantu mahasiswa yang ketinggalan dalam belajar.

Indikator pendekatan pembelajaran yang berfokus pada pengembangan atribut-atribut keterampilan mempunyai rerata skor terendah yaitu 3,863 dari skor maksimal 5. Indikator ini berkaitan dengan penerapan strategi pembelajaran yang memfokuskan pada upaya pengembangan atribut-atribut keterampilan yang bersifat generik seperti basic skills, interpersonal skills, dan personal attributes (Chappell, 2003:12). Mahasiswa mempersepsikan yakin dosen dan instruktur telah menerapkan pendekatan pembelajaran yang berfokus pada pengembangan atributatribut keterampilan. Apabila dicermati dari butir-butir yang menyusunnya, tampak bahwa semua butir memiliki rerata dalam kategori tinggi dan tinggi sekali, dengan rerata skor bervariasi dari 3,58 hingga 4,11 dalam skala skor maksimal 5. Skor tertinggi didapat oleh butir "kegiatan pembelajaran meningkatkan kemampuan mahasiswa dalam menggunakan teknologi”. Sedangkan skor terendah didapat oleh butir "kegiatan pembelajaran meningkatkan kemampuan mahasiswa dalam berbahasa asing". Hal ini dapat dimaknai bahwa dosen dan instruktur telah mengembangkan atribut-atribut keterampilan mahasiswa dalam bidang teknologi khususnya teknologi informasi, hanya saja dosen atau instruktur masih perlu mengembangkan atribut-atribut keterampilan berkomunikasi khususnya menggunakan bahasa Inggris.

Secara umum dapat dirangkum bahwa berkaitan dengan sistem pembelajaran di politeknik, mahasiswa berpendapat bahwa dosen dan instruktur telah menerapkan pendekatan pembelajaran yang mampu meningkatkan pengetahuan dan keterampilan mahasiswa sehingga mereka mendapatkan pengalaman belajar sesuai dengan kebutuhan untuk bekerja serta keterampilan yang didapatkan dapat dengan mudah diterapkan di dunia kerja. Hanya saja masih tetap diperlukan upaya-upaya perbaikan dalam meningkatkan efektifitas pembelajaran di politeknik. Karena sifat dari indikator-indikator dalam analisis konfirmatori 
bersifat reflektif, maka perbaikan-perbaikan yang dilakukan terhadap ketiga pendekatan pembelajaran yang digunakan akan mengindikasikan adanya perbaikan sistem pembelajaran di politeknik.

\section{KESIMPULAN DAN SARAN}

Berdasarkan analisis data dan pembahasan hasil-hasil penelitian, dapat disimpulkan sebagai berikut: (1) Menurut persepsi mahasiswa, kemampuan dosen dan instruktur dalam mengelola program pembelajaran di politeknik dengan menggunakan pendekatan pembelajaran yang berpusat pada peserta didik, pembelajaran yang berpusat pada kerja, serta pembelajaran yang berfokus pada pengembangan atributatribut keterampilan peserta didik secara umum berada dalam kategori baik. (2) Model pengukuran konstruk sistem pembelajaran pendidikan tinggi vokasi terdiri atas indikatorindikator: pembelajaran yang berpusat pada peserta didik, pembelajaran yang berpusat pada kerja, serta pembelajaran yang berfokus pada pengembangan atribut-atribut keterampilan peserta didik. Indikator-indikator ini dinyatakan valid dan reliabel dengan nilai koefisien struktural $(\lambda)$ bervariasi antara 0,78 hingga 0,81 , serta nilai reliabilitas konstruk sebesar 0,85 .

Berdasarkan hasil-hasil penelitian disarankan sistem pembelajaran di politeknik berfokus pada peserta didik, beroirentasi kerja, serta berfokus pada pengembangan atributatribut keterampilan. Terdapat $8,8 \%$ responden berpendapat sistem pembelajaran di politeknik termasuk kategori sedang, maka diperlukan upaya-upaya perbaikan dalam meningkatkan efektifitas pembelajaran di politeknik. Diperlukan berbagai upaya agar dosen maupun instruktur di politeknik ditingkatkan kapasitas dan kemampuannya dalam mengelola program pembelajaran dengan menggunakan pendekatan pembelajaran yang berpusat pada peserta didik, pembelajaran yang berpusat pada kerja, serta pembelajaran yang berfokus pada pengembangan atribut-atribut keterampilan peserta didik.

\section{UCAPAN TERIMA KASIH}

Ucapan terima kasih kami sampaikan kepada Direktur Program Pascasarjana UNY yang telah memfasilitasi pelaksanaan penelitian penulisan dalam rangka penulisan disertasi pada Program Studi Pendidikan Teknologi dan Kejuruan Universitas Negeri Yogyakarta. Ucapan terima kasih juga kami sampaikan kepada berbagai pihak atas segala bantuannya sehingga artikel ini dapat dipublikasikan dalam jurnal ilmiah ini.

\section{DAFTAR PUSTAKA}

Berdrow, I. \& Evers, F. T. (2010). Bases of competence: A framework for facilitating reflective learner-centered educational environments. Journal of Management Education, 20(10), 1-22. Diakses 22 September $2010 \quad$ dari http://jme.sagepub.com/content/early/2010 102/23/1052562909358976.

Bordens, K.S., \& Abbott, B.B. (2008). Research design and methods: A process approach $\left(7^{\text {th }}\right.$ ed). New York: McGraw-Hill Companies, Inc.

Cairney, T. (2000). The knowledge based economy: Implications for vocational education and training. Centre for Regional Research \& Innovation (CRRI) University of Western Sydney. Diakses pada tanggal 12 Juli 2008 dari http://trevorcairney.com/file/uploads/cgilib.22733.1.VETLitRview.pdf

Chappell, C. (2003). Changing pedagogy: Contemporary vocational learning. OVAL Research Working Paper 03-12. The Australian Centre for Organisational, 
Vocational, and Adult Learning (OVAL), University of Technology, Sydney.

Clarke, L., \& Winch, C. (2007). Vocational education: International approaches, developments and systems. New York: Routledge.

Cleary, M., Flynn, R., \& Thomasson, S. (2006). Employability skills: from framework to practice. Melbourne: Precision Consultancy.

De Leeuw, E.D. (2008). Choosing the method of data collection. In Edith D. de Leeuw, Joop J. Hox, and Don A Dillman (Eds.), International hanbook of survey methodology (pp. 113-135). New York: Lawrence Erlbaum Associates.

Finch, C. R., \& Crunkilton, J. R. (1999). Curriculum development in vocational and technical education: Planning, Content and Implementation. Fifth Edition. Boston, Massachusetts: Allyn \& Bacon.

Gall, M. D., Gall, J. P., \& Borg, W. R. (2003). Educational research: An introduction $\left(7^{\text {th }}\right.$ ed.). Boston, MA: Allen and Bacon.

Hager, P. \& Holland, S. (2006). Graduate attributes, learning, and employability. The Netherlands: Springer.

Hair, Jr., J.F., Black, W.C., Babin, B.J., Anderson, R.E., \& Tatham, R.L. (2006). Multivariate data analysis. $6^{\text {th }}$ edtion. New Jersey: Pearson Education, Inc.

Harsono. (2004). Kearifan dalam transformasi pembelajaran: Dari teacher-centered ke student-centered learning. Makalah disampaikan dalam "Seminar implementasi nilai kearifan dalam proses pembelajaran berorientasi studentcentered learning, di Balai Senat UGM, 30 November 2004".

Kilic, A. (2010). Learner-centered micro teaching in teacher education. International Journal of Instruction, 3 (1) : 77-100.

Lohr, S.L. (2008). Coverage and sampling. In Edith D. de Leeuw, Joop J. Hox, and Don A Dillman (Eds.), International hanbook of survey methodology (pp. 97-112). New York: Lawrence Erlbaum Associates.
Mitchell, M.L., \& Jolley, J.M. (2007). Research design explained $\left(6^{\text {th }}\right.$ ed). Belmont, CA: Thompson Wadsworth.

Rojewski, J.W. (2002). Preparing the workforce of tomorrow: A conceptual framework for career and technical education. Journal of Vocational Education Research, 27(1), 735.

Shyi-Huey Wu. (2005). Employability and effective learning systems in higher education. Ninth Quality in Higher Education International Seminar in collaboration with ESECT and The Independent. Birmingham 27th-28th January 2005.

Smart, K.L. \& Csapo, N. (2007). Learning by doing: engaging students through learnercentered activities. Business Communication Quarterly, 70, 451-457.

Smith, E. \& Comyn, P. (2003). The development employability skills in novice workers. Adelaide, Australia: National Centre for Vocational Education Research.

Treleaven, L. \& Voola, R. (2008). Integrating the development of graduate attributes through constructive alignment. Journal of Marketing Education, 30(2), 160-173.

Tempelaar, D. \& Nijhuis, J. (2007). Commonalities in attitudes and beliefs toward different academic subjects. In M. $\mathrm{K}$. McCuddy et al. (Eds), The Challenges of Educating People to Lead in a Challenging World (pp. 225-249). The Netherlands: Springer.

Weimer, M. (2002). Learner-centered teaching: Five key changes to practice. San Fransisco, CA: John Wiley \& Sons, Inc.

Zuhal. (2008). Kekuatan daya saing Indonesia: Mempersiapkan masyarakat berbasis pengetahuan. Jakarta: Penerbit Buku Kompas. 